\title{
Vector analysis investigation of toric intraocular lens with no deviation from the intended axis
}

\author{
This article was published in the following Dove Press journal: \\ Clinical Ophthalmology \\ 2 November 2016 \\ Number of times this article has been viewed
}

\author{
Atsushi Kawahara',2 \\ Yoshinori Takayanagi' \\ 'Takayanagi Clinic, Kushiro, ${ }^{2}$ Sapporo \\ Kato Eye Clinic, Sapporo, Hokkaido, \\ Japan
}

Aim: The aim of this research was to evaluate vector analysis after implantation of toric intraocular lenses (IOLs) without deviation from the intended axis.

Methods: The study included 18 eyes of 16 patients who underwent cataract surgery with the insertion of a toric implant (AcrySof IQ Toric). The postoperative IOL meridian placement completely corresponded to that planned. Using vector analysis, surgically induced astigmatism (SIA) was derived from the refractive outcome versus the predicted postoperative keratometric astigmatism and was compared with targeted induced astigmatism (TIA). The difference vector (DV) was derived by calculating the vector expression of the remaining astigmatic change.

Results: The mean postoperative remaining refractive astigmatism of $0.73 \pm 0.55$ diopters (D) was achieved versus the mean target of $0.44 \pm 0.28 \mathrm{D}$. There was a difference of $0.29 \mathrm{D}$ between the target and achieved values. The mean SIA value was $1.90 \pm 0.99 \mathrm{D}$ compared with the mean TIA value of $2.00 \pm 0.85 \mathrm{D}$. The mean DV value was $0.87 \pm 0.56 \mathrm{D}$. The astigmatism correction index (SIA/TIA) was 0.95 , which was near the ideal value of 1 . The index of success (DV/TIA) was 0.44 , which was far from the ideal value of 0 .

Conclusion: The implantation of toric IOLs is an effective, predictable method for astigmatic correction. However, some remaining astigmatism is present even if toric IOLs are placed accurately.

Keywords: cataract surgery, astigmatism, toric intraocular lens, alpins method, toric calculator, remaining astigmatism

\section{Introduction}

Currently, one aim of cataract surgery is to minimize the dependence on spectacles postoperatively. This requires that all refractive errors, including astigmatism, be addressed at the time of surgery. The use of modern ocular biometry has minimized postoperative spherical defects. Thus, astigmatic control is increasingly important to the refractive outcomes of cataract surgery. The prevalence of preoperative corneal astigmatism of $\geq 1$ diopter (D) in patients who underwent cataract surgery has been estimated to be between $30 \%$ and $37 \% .^{1-3}$ Traditional spherical intraocular lenses (IOLs) restore corrected distance visual acuity by correcting the spherical portion of the refractive error, but they do not correct corneal astigmatism. Accordingly, the implantation of toric IOLs has become a routine method for correcting postcataract extraction astigmatic refractive error to increase uncorrected distance visual acuity. ${ }^{4}$ The principle underlying the treatment rests on the assumption that the significant source of astigmatic refractive error, following removal of the crystalline lens, is the anterior surface of the cornea and that the cylinder power of the toric IOL, chosen using the toric calculator, will match the astigmatism correction requirement of the individual eye if the postoperative IOL meridian placement of the lens corresponds exactly to that planned. ${ }^{5}$ The purpose of this retrospective study was to evaluate vector analysis
Correspondence: Atsushi Kawahara Takayanagi Clinic, I-3-5, Minamiodori, Kushiro, Hokkaido 085-084I, Japan

$\mathrm{Tel}+8 \mathrm{I}$ I54 $43021 \mathrm{I}$

Fax $+8 \mid \quad 154430210$

Email atsusi-k@coral.plala.or.jp 
after the implantation of toric IOLs without deviation from the intended axis.

\section{Materials and methods}

The study was performed in accordance with the Declaration of Helsinki and was approved by the institutional review board (Tokushukai Group Ethics Committee, Tokyo, Japan) which decided that written informed consent from patients was not required due to the retrospective nature of this study. Data were collected retrospectively for patients who underwent cataract surgery at Sapporo Kato Eye Clinic between July 2011 and February 2016 and who had received toric IOLs (AcrySof IQ Toric SN6AT; Alcon Ltd., Tokyo, Japan). Exclusion criteria included irregular corneal astigmatism, congenital eye abnormality, glaucoma, uveitis, previous corneal and retinal disease, previous ocular surgery, a history of eye trauma, perioperative and postoperative complications, or the meridian placement of that IOL at 6 weeks after surgery differed from the intended axis. After these exclusions, a study population of 18 eyes from 16 patients remained. Of these 16 patients, 9 were men and 7 were women; the mean age was $75.6 \pm 4.4$ years (range $70-87$ years).

Preoperative IOL calculations were performed on the basis of OPD-Scan 3 (Nidek Co., Ltd., Gamagori, Japan) topography and OA-1000 (Tomey Corp., Nagoya, Japan) biometry. The IOL sphere power was calculated using the $\mathrm{SRK} / \mathrm{T}$ formula. The cylinder power and IOL placement meridian were chosen using the online Alcon Acrysof Toric Calculator (http://www.acrysoftoriccalculator.com/), which provides expected postoperative refraction values.

All eyes underwent phacoemulsification using a $2.2 \mathrm{~mm}$ temporal clear corneal incision, with topical anesthesia of $4 \%$ lidocaine hydrochloride, on the horizontal meridian and a side-port incision made with the left hand at a forearm position comfortable for a right-handed surgeon. Before surgery, with the patient in the erect position and the eye anesthetized with $0.4 \%$ oxybuprocaine hydrochloride, and the 6 o'clock juxtalimbal epithelium was marked with a 25-gauge needle. In the operating room, a Mendez degree gauge was used to position the appropriate incision and the IOL placement meridian. Conventional coaxial small incision phacoemulsification was conducted, without any perioperative complications in any of the cases, and the IOL was inserted through an unenlarged incision using an incision-assisted technique. The IOL was placed at or rotated to the planned meridian. The viscoelasticity was removed, and all incisions were hydrated to aid incision closure. None of the cases required sutures.
A postoperative review was performed at 6 weeks; this included manifest refraction, topography, and observation of the meridian of the IOL cylinder. The IOL meridian placement was measured using OPD-Scan 3 which could take photography of the torus position of toric IOL and measure a rotation precisely between the intended torus position and the postoperative position. Vector analysis using the Alpins method was used to compare preoperative anterior keratometric astigmatism with the postoperative targeted refractive astigmatism provided by the online toric IOL calculator and the achieved postoperative refractive astigmatism. The latter two values were corrected to the corneal plane because comparisons of vector values for the IOL must be made at one optical plane, the anterior corneal plane. ${ }^{6}$ The Alpins method evaluates changes in the magnitude and axis of astigmatism by computing the following three fundamental vectors: the targeted induced astigmatism (TIA) vector, which describes the change in astigmatic magnitude and axis that the surgery was intended to induce; the surgically induced astigmatism (SIA) vector, which is the magnitude and axis of the astigmatic change that the surgery actually induced; and the difference vector (DV), which is the magnitude and axis of the induced astigmatic change that would enable the initial surgery to meet its intended target. ${ }^{6,7}$ Vector values for the IOL insertion were thus derived for each eye in this study. The corneal plane powers of the toric IOLs were provided by the manufacturer. These were the TIA values for each lens used in this study. The axis of the TIA is the axis of the predicted postoperative keratometric astigmatism. The SIA of the insertion of the toric IOL was calculated by subtracting the vector of the predicted postoperative keratometric astigmatism from that of the measured postoperative refractive astigmatism. The corneal keratometric SIA for the toric IOL calculator was also derived by applying the Alpins method of vector analysis to data from surgical cases performed prior to this study. The SIA is the overall effect of the incisions and the insertion of the toric IOL. Therefore, it differs from the corneal keratometric SIA mentioned earlier, which refers only to the change in corneal astigmatism brought on by the incisions. The DV was derived by calculating the vector expression for the remaining astigmatic change needed to reach the targeted astigmatism. How well the overall target achieved was assessed by the magnitude of the error (the arithmetic difference between this overall SIA magnitude and the magnitude of the TIA) and by the ratio of the magnitude of the SIA to that of the TIA (SIA/TIA). This latter value has been termed the "astigmatism correction index" and should ideally be 1 . In addition, the angle of error between the axes of the SIA and the TIA, and the index of success, 
calculated as the ratio of the magnitudes of the DV and TIA (DV/TIA; which should ideally be 0 ), were derived. Individual vectors were drawn using Delta Graph 5.4.5v J (Red Rock Software Inc., Salt Lake City, UT, USA).

\section{Results}

Six weeks after surgery, the IOL meridian placement corresponded to that planned in all cases. The mean ( \pm standard deviation) uncorrected distance visual acuity was $0.17 \pm 0.13$ logarithm of the minimum angle of resolution ( $\log M A R)$, and the corrected distance visual acuity was $0.00 \pm 0.08 \log$ MAR. Of the 18 eyes, $83 \%$ had uncorrected distance visual acuity of $0.3 \log$ MAR or better and $56 \%$ had $0.2 \log$ MAR or better. Corrected distance visual acuity was $0.2 \log$ MAR or better in $100 \%$ of eyes. Of the 18 eyes, $94 \%$ had against-the-rule keratometric astigmatism preoperatively. The mean postoperative keratometric astigmatism was $1.54 \pm 1.04 \mathrm{D}$. This was comparable with the preoperative mean of $1.77 \pm 0.98 \mathrm{D}$ and the predicted postoperative keratometric astigmatism of $1.59 \pm 0.94 \mathrm{D}$ using the mean predicted corneal keratometric SIA of $0.36 \pm 0.04 \mathrm{D}$. Vector analysis of the actual topographic change revealed the mean corneal keratometric SIA to be $0.39 \pm 0.17 \mathrm{D}$. These data are presented in Table 1.

Results of the vector analysis are presented in Table 2 and Figures 1-3. The astigmatism correction index (SIA/TIA) was 0.95 , and the index of success (DV/TIA) was 0.44 . The astigmatism correction index was near the ideal of 1 , but the index of success was far from the ideal of 0 . In the vector graphs, the vector distribution pattern was characterized by a trend toward a horizontal spread in all groups. This observation may be because almost eyes had against-the-rule preoperatively. Figure 1 shows that the range of TIA extended from $1.03 \mathrm{D}$ to $4.11 \mathrm{D}$. Figure 2 shows that the range of SIA extended from $0.83 \mathrm{D}$ to $4.24 \mathrm{D}$. Figure 3 reveals that the range of DV extended from $0.03 \mathrm{D}$ to $2.32 \mathrm{D}$.

Table I Refractive and keratometric outcomes

\begin{tabular}{ll}
\hline Parameter & Mean \pm SD \\
\hline Uncorrected distance visual acuity (logMAR) & $0.17 \pm 0.13$ \\
Corrected distance visual acuity (logMAR) & $0.00 \pm 0.08$ \\
Preoperative keratometric astigmatism (D) & $1.77 \pm 0.98$ \\
Predicted postoperative keratometric astigmatism (D) & $1.59 \pm 0.94$ \\
Postoperative keratometric astigmatism (D) & $1.54 \pm 1.04$ \\
Predicted corneal keratometric SIA (D) & $0.36 \pm 0.04$ \\
Corneal keratometric SIA (D) & $0.39 \pm 0.17$ \\
Targeted corneal plane refractive astigmatism (D) & $0.44 \pm 0.28$ \\
Achieved postoperative corneal plane refractive & $0.73 \pm 0.55$ \\
astigmatism (D) & \\
\hline
\end{tabular}

Abbreviations: logMAR, logarithm of the minimum angle of resolution; D, diopters; SIA, surgically induced astigmatism; SD, standard deviation.
Table 2 Results of vector analysis

\begin{tabular}{ll}
\hline Parameter & Mean \pm SD \\
\hline TIA (D) & $2.00 \pm 0.85$ \\
SIA (D) & $1.90 \pm 0.99$ \\
Angle of error between the axis of SIA and TIA (degree) & $0.6 \pm 14.2$ \\
DV (D) & $0.87 \pm 0.56$ \\
Astigmatism correction index (SIA/TIA) & 0.95 \\
Index of success (DV/TIA) & 0.44 \\
\hline
\end{tabular}

Abbreviations: $\mathrm{D}$, diopters; TIA, targeted induced astigmatism; SIA, surgically induced astigmatism; DV, difference vector; SD, standard deviation.

\section{Discussion}

The mean preoperative predicted keratometric astigmatism of $1.59 \pm 0.94 \mathrm{D}$, which was putatively the most important source of postoperative refractive astigmatism in the aphakic eye, was reduced to the mean postoperative corneal plane refractive astigmatism of $0.73 \pm 0.55 \mathrm{D}$. The mean targeted corneal plane refractive astigmatism after surgery was $0.44 \pm 0.28 \mathrm{D}$. The difference of $0.29 \mathrm{D}$ between the target and achieved values may represent an undercorrection of astigmatic error. Vector analysis of the refractive outcome versus the predicted postoperative keratometric astigmatism yielded the mean TIA of $2.00 \pm 0.85 \mathrm{D}$; the TIA values were the same as the corneal plane equivalent cylinder power values of the IOL derived by the manufacturer. The mean SIA was $1.90 \pm 0.99 \mathrm{D}$. This indicates the astigmatic change induced by the lens from the predicted postoperative keratometric astigmatism to the postoperative measured refractive astigmatism. It is the observed refractive astigmatic effect of the IOL. The astigmatism correction index (SIA/TIA) was 0.95 in this study; ideally it should be 1 . This value indicates that $95 \%$ of the targeted astigmatic correction was achieved. The mean angle of error between the SIA and the TIA was $0.6 \pm 14.2$ degrees. This demonstrates that the IOLs were placed accurately. The large standard deviation denotes a variable axis of effect of the incision, similar to that found in previous studies ${ }^{8,9} \mathrm{DV}$ is an absolute measure of success and is preferably 0 ; however,

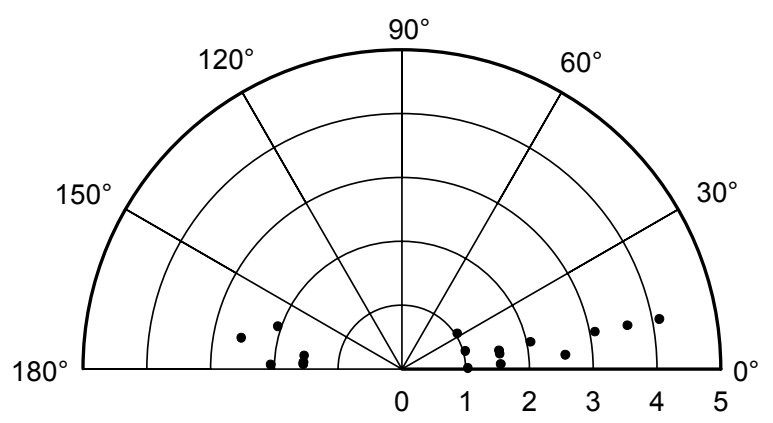

Figure I Vector diagram of targeted induced astigmatism. 


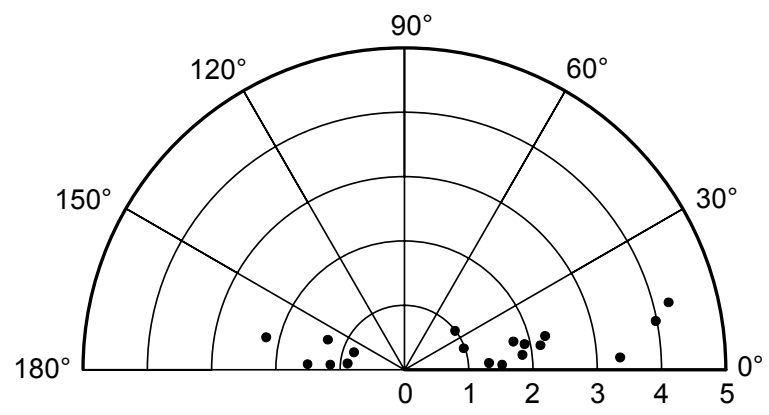

Figure 2 Vector diagram of surgically induced astigmatism.

it had a large magnitude $(0.87 \pm 0.56 \mathrm{D})$ and the index of success (DV/TIA), at 0.44 , was also far from the ideal value of 0 . The remaining astigmatism of $0.29 \mathrm{D}$ was unexpected given that the astigmatism correction index of 0.95 was near the ideal value of 1 , the IOLs were placed accurately, and the prediction of the postoperative keratometric astigmatism power was relatively accurate. Similarly, the large DV and the far from ideal index of success seem anomalous in conjunction with this ideal astigmatism correction index. Sources of error include estimation errors for refraction, including reliance on $0.25 \mathrm{D}$ steps in the refractive measurements, the variability in the $\mathrm{K}$ value reading of topography, errors in the estimation of the axis of the astigmatic effect of the incisions, the presence of other sources of astigmatism in the aphakic eyes, ${ }^{10}$ errors in the estimation of corneal refractive power derived from anterior corneal curvature alone, ${ }^{11-13}$ and errors in the estimation of the effective corneal plane power of the IOL cylinder. ${ }^{14}$

The manufacturer of the toric IOLs that were used in this study notes a corneal plane equivalent cylinder power that is not individualized for IOL sphere power. It is based on one standard IOL plane to corneal plane equivalent to cylinder power conversion factor of $\sim 0.69$ for all IOL sphere and cylinder power combinations and all anterior chamber depths. This estimation is based on "average pseudophakic human eyes." For instance, the SN6AT3 IOL, which is

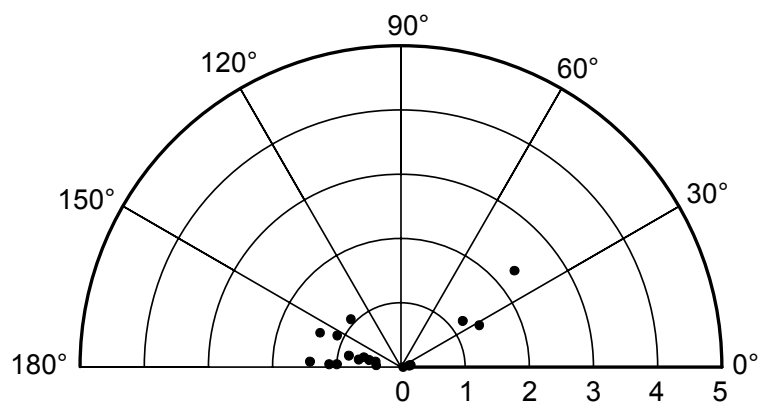

Figure 3 Vector diagram of DV. Abbreviation: DV, difference vector. labeled as having a $1.50 \mathrm{D}$ cylinder at the IOL plane for all sphere powers, is designated as a constant $1.03 \mathrm{D}$ cylinder corneal plane power. If the IOL plane cylinder is constant over the whole range of sphere equivalent powers, the anterior corneal plane equivalent power cannot be a constant 1.03 D cylinder. ${ }^{15}$ Furthermore, no feature exists in its online calculator for alterations of anterior chamber depth and posterior corneal curvature. These factors and our data suggest that the manufacturer's TIA value underestimates the effect of IOL cylinder. Thus, the toric IOL would be more useful if the manufacturer indicated more exactly the online calculator and the corneal plane cylinder equivalent power of its lenses, taking into account the sphere power of the lens, the anterior chamber depth, and the posterior corneal curvature.

\section{Limitations}

The current study had some limitations. First, the study had a small number of subjects. Second, almost all eyes had against-the-rule keratometric astigmatism preoperatively. Additional research with an increased number of patients and involving with-the-rule and oblique eyes is needed to confirm the findings in the current study.

\section{Conclusion}

In conclusion, the results of this study show that the toric IOL is an effective, predictable method of astigmatic correction but that, even when the IOLs are placed accurately, some remaining astigmatism is present owing to sources of surgical and measurement errors. This clinically remaining astigmatic error indicates that the manufacturer's target astigmatism is set too low, even though the target astigmatic change is reached.

\section{Disclosure}

The authors report no conflicts of interest in this work.

\section{References}

1. Khan MI, Muhtaseb M. Prevalence of corneal astigmatism in patients having routine cataract surgery at a teaching hospital in the United Kingdom. J Cataract Refract Surg. 2011;37(10):1751-1755.

2. Hoffmann PC, Hütz WW. Analysis of biometry and prevalence data for corneal astigmatism in 23,239 eyes. J Cataract Refract Surg. 2010;36(9):1479-1485.

3. Ferrer-Blasco T, Montés-Micó R, Peixoto-de-Matos SC, GonzálezMéijome JM, Cerviño A. Prevalence of corneal astigmatism before cataract surgery. J Cataract Refract Surg. 2009;35(1):70-75.

4. Horn JD. Status of toric intraocular lenses. Curr Opin Ophthalmol. 2007; 18(1):58-61.

5. Shimizu K, Misawa A, Suzuki Y. Toric intraocular lenses: correcting astigmatism while controlling axis shift. J Cataract Refract Surg. 1994; 20(5):523-526.

6. Alpins NA. A new method of analyzing vectors for changes in astigmatism. J Cataract Refract Surg. 1993;19(4):524-533. 
7. Alpin N. Astigmatism analysis by the Alpins method. J Cataract Refract Surg. 2001;27(1):31-49.

8. Kaufmann C, Krishnan A, Landers J, Esterman A, Thiel MA, Goggin M. Astigmatic neutrality in biaxial microincision cataract surgery. $J$ Cataract Refract Surg. 2009;35(9):1555-1562.

9. Kaufmann C, Peter J, Ooi K, Phipps S, Cooper P, Goggin M; Queen Elizabeth Astigmatism Study Group. Limbal relaxing incisions versus on-axis incisions to reduce corneal astigmatism at the time of cataract surgery. J Cataract Refract Surg. 2005;31(12): 2261-2665.

10. Teus MA, Arruabarrena C, Hernández-Verdejo JL, Sales-Sanz A, Sales-Sanz M. Correlation between keratometric and refractive astigmatism in pseudophakic eyes. J Cataract Refract Surg. 2010;36(10): 1671-1675.

11. Goggin M, Zamora-Alejo K, Esterman A, van Zyl L. Adjustment of anterior corneal astigmatism values to incorporate the likely effect of posterior corneal curvature for toric intraocular lens calculation. J Refract Surg. 2015;31(2):98-102.
12. Koch DD, Jenkins RB, Weikert MP, Yeu E, Wang L. Correcting astigmatism with toric intraocular lenses: effect of posterior corneal astigmatism. J Cataract Refract Surg. 2013;39(12):1803-1809.

13. Koch DD, Ali SF, Weikert MP, Shirayama M, Jenkins R, Wang L. Contribution of posterior corneal astigmatism to total corneal astigmatism. J Cataract Refract Surg. 2012;38(12):2080-2087.

14. Goggin M, Moore S, Esterman A. Toric intraocular lens outcome using the manufacturer's prediction of corneal plane equivalent intraocular lens cylinder power. Arch Ophthalmol. 2011;129(8):1004-1008.

15. Goggin M, Moore S, Esterman A. Outcome of toric intraocular lens implantation after adjusting for anterior chamber depth and intraocular lens sphere equivalent power effects. Arch Ophthalmol. 2011;129(8): 998-1003.
Clinical Ophthalmology

\section{Publish your work in this journal}

Clinical Ophthalmology is an international, peer-reviewed journal covering all subspecialties within ophthalmology. Key topics include: Optometry; Visual science; Pharmacology and drug therapy in eye diseases; Basic Sciences; Primary and Secondary eye care; Patient Safety and Quality of Care Improvements. This journal is indexed on

Submit your manuscript here: http://www.dovepress.com/clinical-ophthalmology-journal

\section{Dovepress}

PubMed Central and CAS, and is the official journal of The Society of Clinical Ophthalmology (SCO). The manuscript management system is completely online and includes a very quick and fair peer-review system, which is all easy to use. Visit http://www.dovepress.com/ testimonials.php to read real quotes from published authors. 